\title{
Intracranial Extra-axial Chondroma: A Case Report
}

\author{
Fatma Oz Atalay ${ }^{1}$, Gonca Ozgun ${ }^{2}$, Sahsine Tolunay ${ }^{1}$ and Ahmet Bekar ${ }^{3}$ \\ ${ }^{1}$ Department of Surgical Pathology, Uludag University School of Medicine, Turkey \\ ${ }^{2}$ Department of Surgical Pathology, Medipol University, Turkey \\ ${ }^{3}$ Department of Neurosurgery, Uludag University School of Medicine, Turkey
}

\begin{abstract}
Intracranial chondroma is a rare benign neoplasm that occurs most often at the skull base. In extremely rare instances, it arises from the dura mater of the convexity or from the falx cerebri. The tumor cells are thought to originate from meningeal fibroblasts, perivascular mesenchymal tissue, or ectopic chondrocytes. Because the clinical presentation of such cases is nonspecific and because neuroimaging findings are not pathognomonic, intracranial chondromas mimic other intracranial tumors. Herein, we report a chondroma originating from the dura mater in the frontal region. The patient had been followed-up radiologically for 3 years after a preliminary diagnosis of meningioma until the correct diagnosis of chondroma was established with postoperative histological examination.
\end{abstract}

(J Nippon Med Sch 2014; 81: 35-39)

Key words: intracranial tumor, extra-axial, chondroma, dura mater

\section{Introduction}

Chondromas are benign tumors that usually occur in the small bones of the hands and feet. Intracranial chondromas are rare and represent approximately $0.5 \%$ of primary intracranial tumors ${ }^{3.10}$. They usually arise from synchondrosis of the skull base. However, cases have been described in intracranial locations, such as the falx cerebri, the dura of the convexity, the choroid plexus, or the brain parenchyma ${ }^{4.9 .16-18}$. The neuroradiological appearance of chondromas can mimic that of more common intracranial tumors (i.e. meningiomas). In this report, we present a case of intracranial chondroma of the frontal region with a dural connection which was thought to be a meningioma before histological diagnosis.

\section{Case Report}

A 52-year-old woman was brought to the emergency unit of our hospital with seizures. A meningioma had been diagnosed 3 years earlier on the basis of neuroradiological findings (Fig. 1A, 1B and $\mathbf{1 C}$ ). The seizures were interpreted as a consequence of this tumor. Results of routine laboratory tests were in the normal range. Electroencephalography revealed a left-sided frontotemporal focus. Recent magnetic resonance imaging had demonstrated a $2 \times 1-\mathrm{cm}$ extra-axial mass in the left frontal region based on the dura mater and displaying minimal contrast enhancement

* The first two authors contributed equally to this work.

Correspondence to Fatma Oz Atalay, MD, Uludağ Üniversitesi Tıp Fakültesi, Patoloji Bölümü, Görükle, 16059,

Nilüfer-Bursa, Turkey

E-mail: fzatalay@gmail.com

Journal Website (http://www.nms.ac.jp/jnms/) 

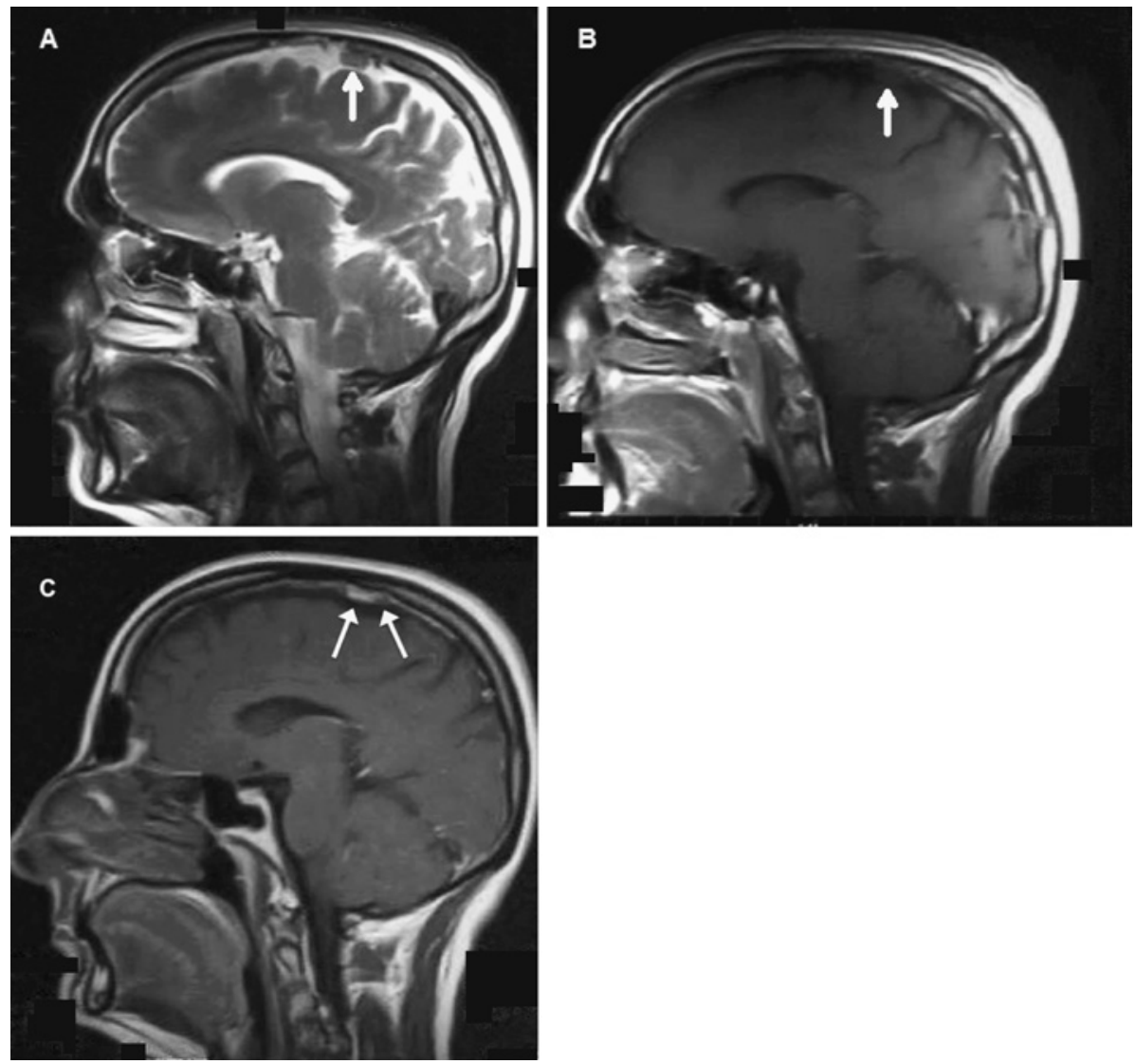

Fig. 1 Arrows show the lesion on a sagittal T2-weighted image (A) and on T1weighted postcontrast images (B and $\mathrm{C}$ ). A minimally enhancing extra-axial lesion (B) with obvious dural enhancement and thickening (C) $2 \times 1 \mathrm{~cm}$ in diameter, isointense with gray matter, and adjacent to the precentral gyrus.

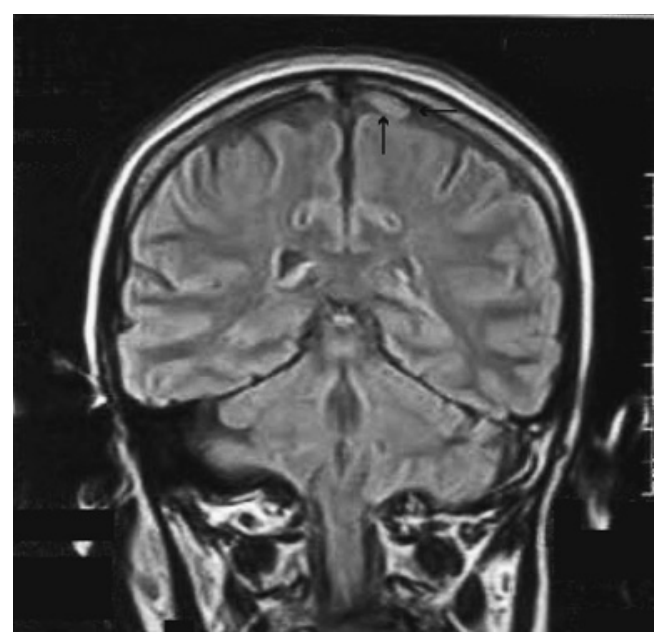

Fig. 2 Coronal fluid-attenuated inversion recovery image showing a large dura-based, hyperintense extra-axial lesion adjacent to the superior sagittal sinus (arrows) with minimal indentation of the precentral gyrus.

(Fig. 1C and 2). The seizures were unresponsive to combined treatment with oxcarbazepine, $600 \mathrm{mg}$

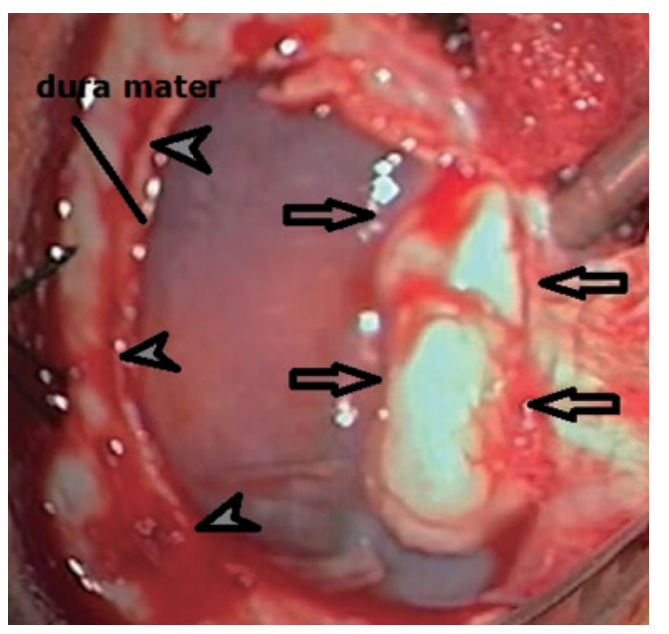

Fig. 3. Intraoperative view of the intracranial and extra-axial chondroma (arrows) dissected with the overlying dura mater (arrowheads).

twice daily, and levetiracetam, $500 \mathrm{mg}$ twice daily in the past two months.

Thus, the patient underwent surgery. A rigid, well-demarcated, white mass adherent to the dura 


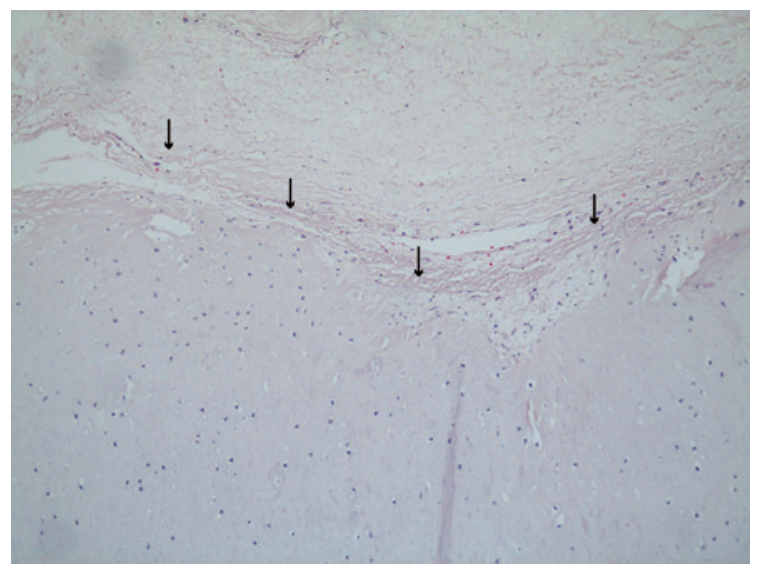

Fig. 4 Chondroma with benign chondrocytes, beneath the dura mater, indicated by arrows (hematoxylin and eosin, $\times 100$ ).

mater was observed on the surface of the frontal cortex intraoperatively (Fig. 3). The mass was completely resected with the attached overlying dura. Microscopic examination of the specimen showed lobules of mature hyaline cartilage without nuclear atypia or mitotic activity (Fig. 4). Immunostaining of the chondrocytes with S-100 was positive (Fig. 5), whereas there was no immunoreactivity for Ki-67. Finally, the diagnosis was chondroma. The postoperative course was uneventful, and additional treatment was not needed.

\section{Discussion}

Intracranial chondromas are rare benign tumors that account for less than $1 \%$ of all intracranial tumors. They often show extradural growth Usually, they arise from the base, most often in the sphenopetrosal, sphenooccipital, and petrooccipital regions. They are believed to originate from the cartilaginous remnants in the basilar synchondrosis ${ }^{36,13}$. However, less frequently, chondromas are located at the dura of the convexity, the falx cerebri, or the choroid plexus. Because chondromas are extraosseous tumors without attachment to the bones of the skull base, their exact pathogenetic mechanism has remained controversial. Hypotheses proposed to explain the histogenesis of dural chondromas include chondroid metaplasia of meningeal fibroblasts or perivascular

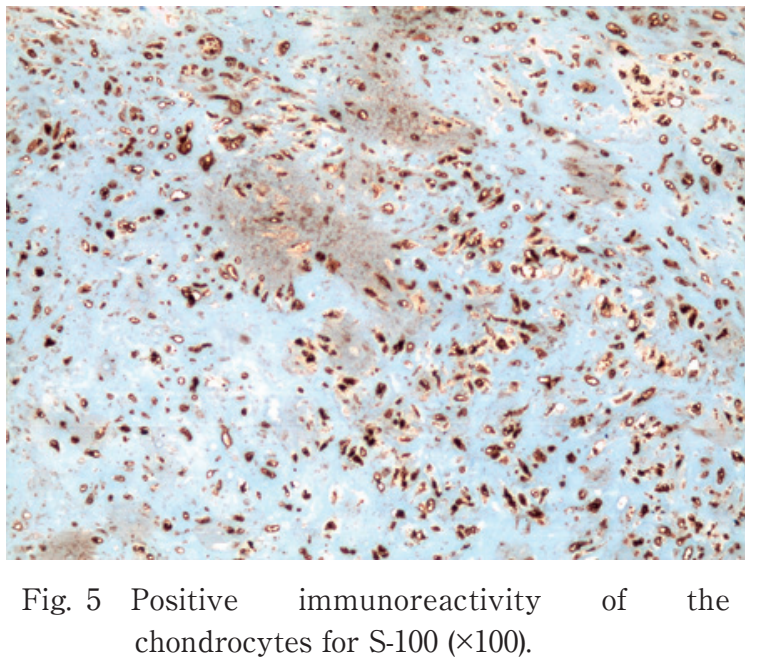

mesenchymal tissue, the presence of ectopic chondrocytes, and cartilaginous activation of fibroblasts by trauma or inflammation ${ }^{12.6,13,19}$.

The clinical presentation of dural chondromas is nonspecific, and symptoms change with the anatomic location of the tumor. Because dural chondromas are slowly growing tumors, they might not produce symptoms until late in development and might first be diagnosed as giant masses. Seizures, increased intracranial pressure, and focal neurological deficits are the frequent presenting symptoms. The incidence of intracranial chondroma does not differ between the sexes. The reported ages of patients range from 15 months to 60 years ${ }^{37.8 .11}$. However, intracranial chondromas most often develop in young adults, with a peak in the third decade.

The neuroimaging findings of convexity or falcine chondromas are not pathognomonic. On computed tomography, chondromas of the skull base, convexity, or falx appear as lobulated, extra-axial lesions with calcifications, usually located off the midline. Density is variable, but lesions are typically isodense and are associated with hyperostosis or scalloping, with no-to-minimal peritumoral edema. Contrast enhancement can be ringlike with minimal to moderate levels. On magnetic resonance imaging, convexity and falcine chondromas appear as homogeneous isointense masses on T1-weighted images with delayed or slight ring-like enhancement on postcontrast T1-weighted images or as a mixed hyperintense/hypointense mass on T2-weighted 
images ${ }^{5,8,12,14}$.

The imaging features of chondromas and meningiomas of the falx cerebri are similar in many ways, such as location and the presence of calcifications and hyperostosis. However, contrast enhancement of meningiomas is characteristically avid and intense, and chondromas do not display the dural tail sign, as do classic convexity meningiomas.

Complete surgical resection is the appropriate treatment if the location is suitable. In cases of falcine or convexity chondromas, removal of the dural sheath or attachment is recommended. The present dural chondroma was well circumscribed, firm, relatively avascular, and not adherent to surrounding tissues. These characteristics favored its complete resection. When resection is subtotal or impossible, adjuvant radiation therapy is not advised because chondromas are radioresistant tumors and because radiation can induce malignant degeneration ${ }^{3.15,19}$. The long-term prognosis is favorable, and no recurrence is expected after total excision.

The microscopic features of intracranial chondromas are the same as those of chondromas elsewhere in the body. Mature chondrocytes within lacunar spaces and an abundant hyaline cartilagenous matrix are characteristic histological findings. The presence of a single nucleus per lacuna, hypercellularity, cytological atypia, and mitotic activity are the key features to rule out chondrosarcoma. In the present case the tumor was hypocellular, and no pleomorphism or mitosis was detected. Low mitotic activity was proven showing negative immunohistochemical reaction for Ki-67.

Intracranial chondromas, particularly those located at the convexity or falx, are rare tumors that are difficult to differentiate from meningiomas when they show similar neuroimaging findings. Therefore, histopathological examination is the gold standard for definitive diagnosis. Chondrosarcoma is the main pathological differential diagnosis and can usually be ruled out with examination of hematoxylin and eosin-stained sections. The long-term prognosis after total resection is excellent.

Conflict of Interest: The authors declare that there are no conflicts of interest.

\section{References}

1. Acampora S, Troisi F, Fusco G, Del Gaizo S: Voluminous intracranial chondroma. Surg Neurol 1982; 18: 254-257.

2. Berkmen YM, Blatt ES: Cranial and intracranial cartilaginous tumours. Clin Radiol 1968; 19: 327-333.

3. Colpan E, Attar A, Erekul S, Arasil E: Convexity dural chondroma: a case report and review of the literature. J Clin Neurosci 2003; 10: 106-108.

4. De Coene B, Gilliard C, Grandin C, Nisolle JF, Trigaux JP, Lahdou JB: Unusual location of an intracranial chondroma. AJNR Am J Neuroradiol 1997; 18: 573-575.

5. Delgado-López PD, Martín-Velasco V, GalachoHarriero AM, Castilla-Díez JM, Rodríguez-Salazar A, Echevarría-Iturbe C: Large chondroma of the dural convexity in a patient with Noonan's syndrome. Case report and review of the literature. Neurocirugia (Astur) 2007; 18: 241-246.

6. Dutton J: Intracranial solitary chondroma. Acta Neurochir Suppl (Wien) 1979; 28: 442-444.

7. Erdogan S, Zorludemir S, Erman T, et al.: Chondromas of the falx cerebri and dural convexity: report of two cases and review of the literature. J Neurooncol 2006; 80: 21-25.

8. Fountas KN, Stamatiou S, Barbanis S, Kourtopoulos $\mathrm{H}$ : Intracranial falx chondroma: literature review and a case report. Clin Neurol Neurosurg 2008; 110: 8-13.

9. Hirvonen J, Heikinheimo H: A case of intracerebral chondroma. A case report. Acta Pathol Microbiol Scand 1969; 76: 19-24.

10. Kurt E, Beute GN, Sluzewski M, van Rooij WJ, Teepen JL: Giant chondroma of the falx. Case report and review of the literature. J Neurosurg 1996; 85: 1161-1164.

11. Mapstone TB, Wongmongkolrit T, Roessman U, Ratcheson RA: Intradural chondroma: a case report and review of the literature. Neurosurgery 1983; 12: $111-114$.

12. Mariniello G, Cappabianca P, Stella L, Del Basso De Caro ML, Buonamassa S, de Divitiis E: Chondroma of the petrous apex. Clin Neurol Neurosurg 2003; 105: $135-139$

13. Nakazawa T, Inoue T, Suzuki F, Nakasu S, Handa J: Solitary intracranial chondroma of the convexity dura: case report. Surg Neurol 1993; 40: 495-498.

14. Ozgen T, Pamir MN, Akalan N, Bertan V, Onol B: Intracranial solitary chondroma. Case report. J Neurosurg 1984; 61: 399-401.

15. Rosenberg AE: Chordoma and related lesions, chondrosarcoma and osteosarcoma. In Russell \& Rubinstein's pathology of tumors of the nervous system (McLendon R, Bigner DD, eds), 7th Ed. 2006; pp 765-787, CRC Press, London.

16. Siqueira EB, Bucy PC: Case report. Chondroma arising within a mixed clioma. J Neuropathol Exp Neurol 1966; 25: 667-673.

17. Ustün MO, Paksoy N, Kilicarslan B: Cystic chondroma arising from the falx cerebri: a case study with review of literature. Clin Neuropathol 
1997; 16: 27-29.

18. Valdueza JM, Freckmann N, Herrmann HD: Chondromatosis of the choroid plexus: case report. Neurosurgery 1990; 27: 291-294.

(Received, November 9, 2012)

. Yaşargil MG, Krayenbühl HA: Chondromas. In

(Accepted, February 8, 2013) Progress in Neurological Surgery (Krayenbühl HA, ed), 1975; pp 435-463, Karger Publishers, Basel. 